\title{
Enfrentamento da violência contra mulher e o papel da equipe interdisciplinar: relato de experiência
}

\author{
Combat to violence against women and the \\ interdisciplinary team role: experience report
}

\author{
Lisiane Marcolin de Almeida', Simone Travi Canabarro', Helena Terezinha Hubert Silva \\ 'Universidade Federal de Ciências da Saúde de Porto Alegre, Porto Alegre (RS), Brasil.
}

\section{RESUMO}

Contextualização: A Casa de Apoio Viva Maria é um abrigo que acolhe mulheres, família e filhos menores de idade em situação de violência doméstica, sexual ou em risco de vida iminente em razão da violência, sob a gerência da Secretaria Municipal de Saúde (SMS) e mantida com recursos da Prefeitura Municipal de Porto Alegre. O objetivo da casa é garantir a segurança à integridade física e oferecer apoio integral à mulher e filhos por meio do acesso ao serviço de psicologia, serviço social e jurídico, visando o fortalecimento da autoestima para a reconstrução da vida sem violência. O conceito de violência é muito amplo e a palavra deriva do latim e sua origem está relacionada com o termo "violação", onde a violência contra a mulher é um problema de saúde pública caracterizada como crime. Descrição da experiência: As atividades desenvolvidas na casa são realizadas por uma equipe multidisciplinar que atua de forma interdisciplinar na interface saúde e violência, com atendimento individual e em grupo com as mulheres e crianças. O serviço é um modelo de atuação interdisciplinar com interlocução entre os diferentes profissionais estimulando assim, um novo rumo para as mulheres vitimas de violência. A construção do trabalho surge no enfrentamento à violência de modo ativo por parte dos profissionais reformulando a ideia de conduta resolutiva sem ir a fundo às reais necessidades da vítima. As atividades realizadas no abrigo por meio de um trabalho diário, desempenhado por uma equipe técnica que possui clareza e compreensão sobre o fenômeno da violência, atingem os objetivos do Programa Municipal de Albergues para a mulher vítima de violência. Considerações finais: Certamente, a capacidade dos profissionais em não deixar que a convivência cotidiana com a temática promova retrocessos no entendimento da violência, garante o fortalecimento do resgate da autonomia e do empoderamento da mulher.

Recebido: Maio 29, 201

COMO CITAR ESTE ARTIGO

Almeida LM, Canabarro ST, Silva HTH. Enfrentamento da violência contra mulher e o papel da equipe interdisciplinar: relato de experiência. Interdisciplinary Journal of Health Interdisciplinary Journal of Health Education. 2016 Jan-Jul;1(1):63-67. http://dx.doi.org/10.4322/ijhe2016006.

\section{CORRESPONDÊNCIA}

Lisiane Marcolin de Almeida

Universidade Federal de Ciências da

Saúde de Porto Alegre

Saúde de Porto Alegre

Rua Monsenhor Antônio Guilherme

Grings, 51, apto 801, torre 1, Bairro

Sarandi, CEP 91110-042, Porto Alegre

(RS), Brasil

lisianemarcolin@hotmail.com

PALAVRAS-CHAVE: Interdisciplinaridade. Violência. Enfrentamento

\section{ABSTRACT}

Contextualization: Casa de Apoio Viva Maria ("Support Home Viva Maria") is a shelter that welcomes women, family and underage children in situations of domestic and sexual violence or imminent life threat due to violence. It is managed by the Municipal Health Secretary (SMS) and maintained with funds from Porto Alegre's city hall. The purpose of the support home is to ensure the physical integrity and full support to women and children through access to psychological, social work and law services, aiming to strengthening self-esteem for the reconstruction of life without violence. The concept of violence is broad; the word derives from the Latin and its origin is related to the term "violation", where violence against women is a public health problem characterized as a crime. Description of experience: The activities developed in the support house are performed by a multidisciplinary team working in an interdisciplinary manner at the interface of the health and violence, with women and children, individually and in groups. The service is a model of interdisciplinary approach through dialogue between the different professionals stimulating thus a new course for women victims of violence. The work construction comprises dealing with the active mode of violence by professionals reformulating the idea of solving conduct without going back to the actual victim's needs. The activities used in the shelter by means of a daily work, performed by a technical team that understand and comprehend the phenomenon of violence, achieve the goals of the "Hostels Municipal Program" for the woman victim of violence. Final considerations: Certainly, the professionals ability do not allow the daily discussion of the theme to promote setbacks in the understanding of violence, and ensures the strengthening of the autonomy rescue and women empowerment.

KEYWORDS: Interdisciplinarity. Violence. Confrontation.

Nenhuma.

CONFLITO DE INTERESSE

haver conflitos de interesse.

O estudo foi realizado na Universidad Federal de Ciências da Saúde de Porto Alegre, Porto Alegre (RS), Brasil.

alth Education (IJHE). 


\section{Contextualização}

A Casa de Apoio Viva Maria é um abrigo que acolhe mulheres, família e filhos menores de idade em situação de violência doméstica, sexual ou em risco de vida iminente em razão da violência, no qual as usuárias permanecem por um período entre 15 a 90 dias até possuírem condições necessárias para retomarem suas rotinas. A casa foi inaugurada em setembro de 1992, como um serviço da proteção social especial da alta complexidade com a política de abrigo para mulheres, sob a gerência da Secretaria Municipal de Saúde (SMS) e mantida com recursos da Prefeitura Municipal de Porto Alegre, conforme a legislação do Decreto 10.172/91 que regulamenta a Lei 6.919 de $1991^{1}$ que instituiu o Programa Municipal de Albergues para a mulher vítima de violência visando o apoio às instituições que desenvolvem ações de atendimento à mulher. $\mathrm{O}$ objetivo da casa é garantir a segurança à integridade física e oferecer apoio integral à mulher e filhos por meio do acesso ao serviço de psicologia, serviço social e jurídico, focando o fortalecimento da autoestima para a reconstrução da vida sem violência. A casa abriga também casos de violência contra homossexuais e transgêneros. É um serviço de caráter sigiloso, onde o endereço da casa permanece protegido com a finalidade de garantir segurança às mulheres.

O conceito de violência é muito amplo e a palavra deriva do latim e sua origem está relacionada com o termo "violação". Quando se trata de direitos humanos, a violência abrange todos os atos de violação dos direitos: civis, sociais, econômicos, culturais e políticos ${ }^{2}$. No tocante sobre a violência contra a mulher, desde que o movimento feminista e as agências internacionais colocaram a violência contras as mulheres e de gênero na agenda política pública, o Brasil produziu legislação e políticas sociais para o enfrentamento, provocando um aumento de denuncias e de procura de ajuda por parte das vítimas ${ }^{2}$. Segundo o Censo do Instituto Brasileiro de Geografia e Estatística (IBGE) $^{3}$ apenas no primeiro semestre de 2012, foram realizados 47.555 registros de atendimentos na central de Atendimento à mulher. $\mathrm{O}$ tipo de registro que aparece em maior número é para revelar violência física contra mulher que pode variar de lesão corporal leve, grave ou gravíssima, tentativa de homicídio e homicídio consumado ${ }^{3}$.

Esta constatação mostra que a violência contra a mulher é um problema de saúde pública caracterizada como crime conforme a Lei 11.340 de 4 de Agosto de $2006^{4}$ que constitui a violência contra a mulher como "[...] qualquer ação ou conduta, baseada no gênero, que cause morte, dano ou sofrimento físico, sexual ou psicológico à mulher, tanto no âmbito público como no privado [...]" e visa coibir a violência doméstica e familiar. Assim, a Lei Maria da Penha foi o resultado de um consórcio composto por entidades e movimentos de mulheres, feministas e de juristas para estudar e elaborar uma minuta de projeto de lei que estabelecesse mecanismos para coibir, punir e prevenir a violência contra mulher, aprovada por unanimidade ${ }^{2}$.

\section{Descrição da experiência}

A visita técnica foi realizada no dia 6 de Abril de 2016, na Casa de Apoio Viva Maria, localizada na cidade de Porto Alegre - RS, pelos mestrandos e por um dos professores da disciplina Interdisciplinaridade: trabalho na saúde e educação do Programa de Pós-Graduação em Ensino da Saúde da Universidade Federal de Ciências da Saúde de Porto Alegre.

A equipe atuante no abrigo é composta por 1 enfermeira, 1 assistente social, 2 terapeutas ocupacionais, 1 nutricionista, 1 técnico de enfermagem, 5 monitoras, estagiários de psicologia de Universidades do município, psicólogas, cozinheiras e auxiliares de serviços gerais. A jornada de trabalho é em regime de plantão, visto que a casa possui trabalho ininterrupto. São realizadas reuniões regulares onde uma equipe jurídica é convidada para auxiliar nas articulações entre os profissionais. 
As atividades desenvolvidas na casa são realizadas por uma equipe multidisciplinar que atua de forma interdisciplinar na interface saúde e violência, com atendimento individual e em grupo com as mulheres e crianças. No início, não havia nenhum serviço de modelo de referência para o abrigo, então o trabalho desenvolvido pela equipe era destinado a um profissional para cada atendimento, com enfoque técnico e fragmentado, entretanto com o decorrer do tempo a equipe evidenciou a necessidade de transformação objetivando além de um abrigo, um serviço com atividades a fim de favorecer a convivência entre as famílias possibilitando uma representação de mudança no rompimento das situações de violência. Também foi adotado um modelo de arranjo organizacional como o profissional de referência para cada família, responsável pelo acolhimento desta família e orientação dentro do abrigo. A partir da percepção de mudança, a casa iniciou um serviço de modelo de trabalho na atuação interdisciplinar com interlocução entre os diferentes profissionais estimulando assim, um novo rumo para as mulheres vitimas de violência. Esta postura de mudança e enfoque ampliado, por si só caracteriza um trabalho interdisciplinar ${ }^{5}$. As reuniões ocorrem na frequência de um encontro por semana com presença de todos profissionais e eventualmente uma equipe jurídica, como já mencionada. A tomada de decisão de modo compartilhado é um processo que é trabalhado exigindo muita maturidade dos profissionais. Para Minayo, existe uma exigência de articulação na interdisciplinaridade na busca por um conhecimento integrado que corrobora para intervenções sociais na saúde ${ }^{6}$. Contudo, o apoio matricial promove nestes casos, uma interação entre os saberes distintos impondo aos profissionais o desenvolvimento de um projeto terapêutico, visto que esta metodologia busca apoio especializado a equipe de saúde indo além do sistema hierarquizado ${ }^{7}$.

O fluxo de atendimento é por meio de uma rede de referência e contra referência onde a rede de atendimento segue o fluxo de avaliação e triagem realizada no próprio abrigo, pela equipe especializada, por meio do encaminhamento da Delegacia da Mulher. Existe uma preocupação na avaliação de cada caso para ingresso na casa, pois apenas casos extremos, como o risco de morte, são recebidos, visto que o abrigo conta com 11 quartos, sendo o limite de vagas de no máximo 11 famílias. A casa por sua vez, realiza encaminhamento para rede da Defensoria Pública, Juizado Especial e Unidade de Saúde de referência. Profissionais de todas as unidades de saúde do município de Porto Alegre foram capacitados pela própria equipe da Casa e são aptos a realizar o acolhimento.

\section{Resultados e impactos}

A maioria das especialidades e profissionais de saúde trabalha com um referencial sobre o processo saúde e doença restrito, constituindo um obstáculo epistemológico, entretanto o apoio matricial assegura maior eficácia e eficiência da equipe de referência, instigando a autonomia dos usuários ${ }^{7}$. O apoio matricial presente na casa é enxergado como uma metodologia de gestão do trabalho interdisciplinar em saúde, o que garante o suporte clínico além do apoio técnico-pedagógico a equipe de referencia?.

As atividades de educação permanente ocorrem com periodicidade fora do ambiente da Casa de Apoio, com profissionais da saúde onde o objeto de trabalho é a violência. Estas educações permanentes, por meio de metodologias ativas levam, a mudanças de atuação do profissional, favorecendo o processo de interdisciplinaridade, requerendo diferente saberes disciplinares de ordem prática ou didática no processo de aprendizagem ${ }^{8}$. A Casa desenvolve outros trabalhos no aspecto de ensino/aprendizagem, oferecendo espaço para integração com as universidades, por meio dos estágios e práticas curriculares. O prontuário único da 
equipe multidisciplinar é também um exemplo da atividade interdisciplinar adotada com a presença de uma evolução única com assinatura de todos profissionais.

A Casa de Apoio Viva Maria apresenta característica sazonal, relatada pelos profissionais, como sendo característico o aumento ou diminuição do número de mulheres na casa em situações específicas. O conhecimento expressado pelos profissionais sobre os índices de violência na comunidade e como o aumento ou diminuição dos números interfere no trabalho dentro da Casa, levanta a questão de quão qualificado é o trabalho desempenhado por eles. Em uma visão geral, o trabalho realizado pelos profissionais deixa claro que estes possuem uma leitura do processo de trabalho que vai além do serviço na Casa de Apoio.

Observa-se que existe um cuidado da equipe em manter uma referência de "lar" para com a especificidade dos usuários, com brinquedos nos ambientes físicos, o que facilita a interação da mãe, filho e profissional na abordagem terapêutica, garantindo alcançar uma das metas da Casa que é possibilitar um espaço adequado e próprio para as crianças. A presença de regras no abrigo visa estabelecer atividades diárias como limpeza e organização dos quartos, além disso, as mulheres mantem a tarefa de cuidado dos filhos desde higiene até o auxílio nas atividades escolares. As crianças, por sua vez, mantêm a rotina de estudantes, e o abrigo tem a preocupação de realizar contato com a rede de educação para a mudança de escola na garantia de segurança e sigilo, garantindo desta maneira, as ações pedagógicas. Como a escola pertencente a rede de manutenção e desenvolvimento do trabalho interdisciplinar, esta desempenha atividades e reflexões conjuntas à Casa dentro do tema violência.

Um ponto de discussão observado em relação à estrutura física da Casa de Apoio foi o excesso de salas disponíveis para atividades profissionais, dando a impressão de que o trabalho ocorre fragmentado, entretanto, cabe ressaltar que a Casa possui a mesma estrutura desde a inauguração, com alterações mais recentes relacionadas aos quartos dos usuários, além disso, recebe recursos públicos mantidos pela mantenedora, fato este considerado impeditivo para investimentos. Este tipo de estrutura em ambientes onde a prática não é interdisciplinar, contribui com o baixo grau de interação entre os profissionais constituindo um obstáculo estrutural, dificultando a gerência como também, potencializando a divisão das disciplinas. Contudo, esta estrutura comum dos serviços de saúde na sua grande maioria corresponde a uma barreira estrutural à prática de uma clínica ampliada, bem como do trabalho interdisciplinar 9 .

Outra questão observada, porém positiva, pela fala dos profissionais, é em relação a temática violência e o trabalho de recuperação das famílias. Por meio do acolhimento e articulação, o trabalho visa o atendimento integral a família no campo da interdisciplinaridade ressignificando o conceito de respeito, laços familiares e autoestima. A construção deste trabalho é realizada por outra ótica, longe da visão da sociedade que entende a violência de forma "banalizada" e a Casa de Apoio como um espaço de "hotelaria". Esta transformação de visão e entendimento surge no enfrentamento à violência de modo ativo por parte dos profissionais reformulando a ideia de conduta resolutiva sem ir a fundo às reais necessidades da vítima ${ }^{5}$.

\section{Considerações finais}

As atividades realizadas no abrigo por meio de um trabalho diário, desempenhado por uma equipe técnica que possui clareza e compreensão sobre o fenômeno da violência, atingem os objetivos do Programa Municipal de Albergues para a mulher vítima de violência. Certamente, a capacidade dos profissionais em não deixar que a convivência cotidiana com a temática promova retrocessos no entendimento da violência, garante o fortalecimento do resgate da autonomia e do empoderamento da mulher. 


\section{Referências}

1. Porto Alegre (RS). Decreto ${ }^{\circ}$ 10.172: regulamenta a Lei 6.919, de 22 de outubro de 1991. Diário Oficial do Estado, Porto Alegre (RS), 30 dez. 1991. Seção 248, p. 24-36.

2. Dagord ALL. Viva Maria dez anos [dissertação]. Porto Alegre: Universidade Federal do Rio Grande do Sul; 2003.

3. Instituto Brasileiro de Geografia e Estatística - IBGE. Censo 2012. Rio de Janeiro: IBGE; 2016 [citado em 2016 Abr 17]. Disponível em: http://www.ibge.gov.br/home/presidencia/noticias/imprensa/ppts/00000010961811202012185527900054. pdf.

4. Brasil. Presidência da República. Casa Civil Subchefia para assuntos jurídicos. Lei no 11.340 de 7 de Agosto de 2006 . [citado em 2016 Abr 18]. Disponível em: https://www.planalto.gov.br/ccivil_03/_Ato2004-2006/2006/Lei/L11340.htm.

5. Meneghel SN, Camargo M, Fasolo LR, et al. Mulheres cuidando de mulheres: um estudo sobre a Casa de Apoio Viva Maria, Porto Alegre, Rio Grande do Sul, Brasil. Cad Saude Publica. 2000;16(3):747-57. PMid:11035514. http://dx.doi.org/10.1590/ S0102-311X2000000300023.

6. Minayo MCS. Interdisciplinaridade: funcionalidade ou Utopia. Saúde e Sociedade. 1994;3(2):42-63. http://dx.doi.org/10.1590/ S0104-12901994000200004.

7. Campos GWS, Domitti AC. Apoio matricial e equipe de referência: uma metodologia para gestão do trabalho interdisciplinar em saúde. Cad Saude Publica. 2007;23(2):399-407. PMid:17221089. http://dx.doi.org/10.1590/S0102-311X2007000200016.

8. Fazenda ICA. Interdisciplinaridade: didática e prática de ensino. In: ENDIPE; 2014.

9. Campos GWS, Domitti AC. Metodologia para gestão do trabalho interdisciplinar em saúde. Cad Saude Publica. 2007;23(2):399407. PMid:17221089. http://dx.doi.org/10.1590/S0102-311X2007000200016.

\section{Contribuição dos autores}

Lisiane Marcolin de Almeida: participou da elaboração e planejamento da redação do relato de experiência. Simone Travi Canabarro: orientou todas as etapas do trabalho, e participou da revisão e redação do relato de experiência. Helena Terezinha Hubert Silva: orientou todas as etapas do trabalho, e participou da revisão e redação do relato de experiência com contribuições intelectuais. 